\title{
Limiting Ago protein restricts RNAi and microRNA biogenesis during early development in Xenopus laevis
}

\author{
Elsebet Lund, Michael D. Sheets, Susanne Blaser Imboden, and James E. Dahlberg ${ }^{1}$ \\ Department of Biomolecular Chemistry, University of Wisconsin School of Medicine and Public Health, University of \\ Wisconsin, Madison, Wisconsin 53706, USA
}

\begin{abstract}
We show that, in Xenopus laevis oocytes and early embryos, double-stranded exogenous siRNAs cannot function as microRNA (miRNA) mimics in either deadenylation or guided mRNA cleavage (RNAi). Instead, siRNAs saturate and inactivate maternal Argonaute (Ago) proteins, which are present in low amounts but are needed for Dicer processing of pre-miRNAs at the midblastula transition (MBT). Consequently, siRNAs impair accumulation of newly made miRNAs, such as the abundant embryonic pre-miR-427, but inhibition dissipates upon synthesis of zygotic Ago proteins after MBT. These effects of siRNAs, which are independent of sequence, result in morphological defects at later stages of development. The expression of any of several exogenous human Ago proteins, including catalytically inactive Ago2 (Ago2mut), can overcome the siRNA-mediated inhibition of miR427 biogenesis and function. However, expression of wild-type, catalytically active hAgo2 is required to elicit RNAi in both early embryos and oocytes using either siRNA or endogenous miRNAs as guides. The lack of endogenous Ago2 endonuclease activity explains why these cells normally are unable to support RNAi. Expression of catalytically active exogenous Ago2, which appears not to perturb normal Xenopus embryonic development, can now be exploited for RNAi in this vertebrate model organism.
\end{abstract}

[Keywords: Argonautes; Ago2; RNAi; siRNA; Dicer; Xenopus embryos]

Supplemental material is available for this article.

Received February 3, 2011; revised version accepted April 7, 2011.

MicroRNAs (miRNAs) and siRNAs are 22- to 24-nucleotide (nt) RNAs that modulate gene expression post-transcriptionally by acting as guides to direct Argonaute (Ago)containing RNA-induced silencing complexes (RISCs) to targeted mRNAs (Bartel 2004; Valencia-Sanchez et al. 2006; Kim et al. 2009; Czech and Hannon 2011). Animal miRNAs, processed from cellular transcripts, primarily recognize partially complementary miRNA target sequences that are located in the $3^{\prime}$ untranslated regions (UTRs) of mRNAs, leading to translational repression, deadenylation, and decay of mRNAs (Eulalio et al. 2008; Fabian et al. 2010). In contrast, siRNAs, derived from exogenously introduced perfectly base-paired siRNA duplexes, promote cleavage of targeted mRNAs at fully complementary sequences catalyzed by associated Ago2 (Liu et al. 2004). In vertebrate cells, miRNAs and siRNAs incorporated into Ago2-RISCs can function interchangeably, depending on the extent of sequence complementarity with their targeted mRNAs.

${ }^{1}$ Corresponding author.

EMAIL dahlberg@wisc.edu; FAX (608) 262-5253.

Article published online ahead of print. Article and publication date are online at http://www.genesdev.org/cgi/doi/10.1101/gad.2038811.
Eggs and embryos of the frog Xenopus laevis contain pools of maternally produced mRNAs and cell components that support translation, cell division, and production of the embryonic miR-427, which becomes incorporated into RISCs within a few hours of fertilization (Watanabe et al. 2005; Lund et al. 2009). At the midblastula transition $(\mathrm{MBT})$, the embryonic stage when the cell cycle is remodeled and robust zygotic transcription is initiated (Newport and Kirschner 1982a,b), miR-427 promotes deadenylation and destabilization of maternal mRNAs that contain a miR-427 recognition element $\left(\mathrm{MRE}_{427}\right)$, such as those encoding cyclins A1 and B2 (Audic et al. 2001; Lund et al. 2009). Premature expression of miR-427 following introduction of in vitro synthesized pre-miR-427 into oneor two-cell Xenopus embryos accelerates the onset of deadenylation and destabilization of targeted mRNAs, showing that factors needed for the maturation and function of miRNAs and RISCs are produced during oogenesis (Lund et al. 2009). A similar system of embryo-specific miRNA430 promotes deadenylation and turnover of many maternal mRNAs during early development of zebrafish (Giraldez et al. 2006).

Despite the presence of factors needed for generation and function of miRNAs and RISCs in early embryos of 
$X$. laevis and zebrafish, the use of siRNA-mediated RNAi to modulate expression of maternal or zygotic mRNAs is unreliable (Gruber et al. 2005; Zhao et al. 2008; Perrimon et al. 2010; Wang et al. 2010). That deficiency has led to extensive use of alternative, more expensive methods to down-regulate translation of proteins of interest (Amaya et al. 1991; Ekker 2000; Heasman et al. 2000; Hulstrand et al. 2010).

Here we show that accumulation of $X$. laevis Ago proteins is subject to developmental control in both oocytes and early embryos, and that this regulation has unexpected consequences for the activities of miRNAs and siRNAs. Injected siRNAs titrate maternal Ago proteins that are present in restrictive amounts in oocytes and early embryos, resulting in impairment of Dicer function and, hence, inhibition of miRNA biogenesis and function at MBT. Also, we demonstrate that Ago2 is either absent or not catalytically active in these cells, explaining why RNAi is not supported. However, expression of exogenous Ago2 allows for RNAi, a feature that promises to have utility in the analysis of gene function during early development.

\section{Results}

Inhibition of miR-427-promoted deadenylation in embryos by siRNAs

Previously, we showed that premature accumulation of miR-427 following injection of pre-miR-427 into one-cell embryos shifted the onset of deadenylation of maternal cyclin B2 mRNA from the MBT to earlier times (Lund et al. 2009). To test whether a miR-427 mimic in the form of a short duplex siRNA could likewise promote premature deadenylation, we used a chimeric reporter mRNA target (Gb•B2) (Fig. 1A) that was coinjected with siRNA 427 , in which the predicted guide strand is identical in sequence to miR-427. Surprisingly, instead of accelerating deadenylation and destabilization of the reporter, siRNA ${ }_{427}$ delayed turnover of the reporter RNA (Fig. 1A, middle panel). This stabilization resembled that observed when the $\mathrm{MRE}_{427}$ in the reporter was mutated (Fig. 1A, bottom panel).

To determine whether siRNA ${ }_{427}$ also affected the stability of endogenous miR-427 targets, we monitored the fate of maternal cyclin B2 mRNA by Northern blotting (Sheets et al. 1994; Lund et al. 2009). Like the exogenous reporter RNA, the endogenous mRNA remained polyadenylated and stable after MBT in embryos injected with siRNA $_{427}$ (Fig. 1B, top panels). Moreover, a nonspecific control siRNA, siRNA ${ }_{\mathrm{NS}}$, elicited similar effects (Fig. 1B, bottom panels), showing that impairment of deadenylation is independent of siRNA sequence.

The generality of inhibition of deadenylation at MBT by siRNA was further demonstrated using reporter RNAs derived from the 3' UTR of cyclin A1 mRNA, another miR427 target (Fig. 1C). Both the miR-427-mimic (siRNA 427 ) and

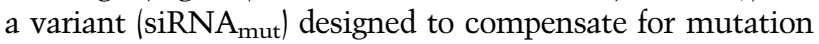
of the $\mathrm{MRE}_{427}$ slowed rather than accelerated deadenylation of these reporter RNAs.

\section{Inhibition of Dicer activity in embryos by siRNA}

The miR-427 mediating deadenylation at MBT is not maternally provided (Watanabe et al. 2005) but must be processed from newly made pre-miR-427 (Lund et al. 2009). Therefore, we asked whether inhibition of deadenylation
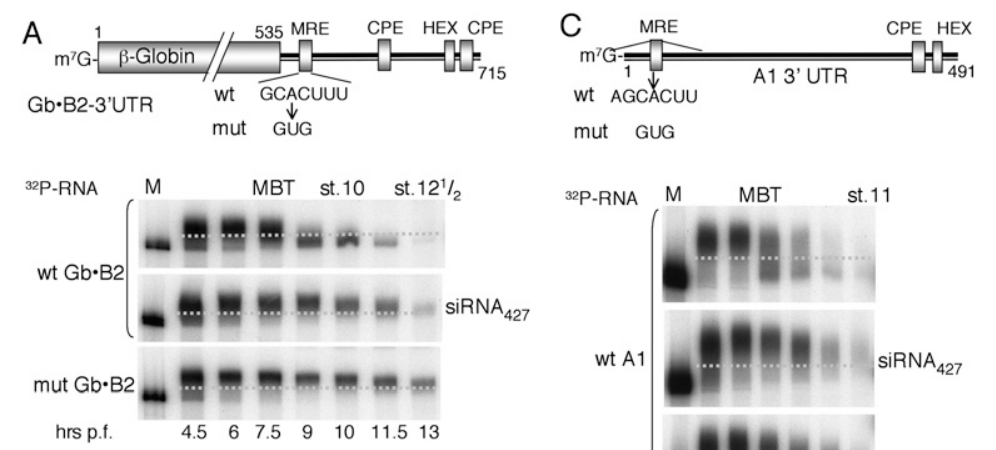

B Northern

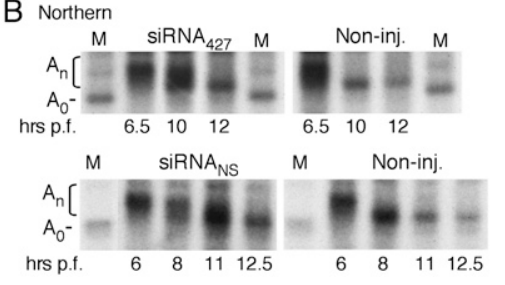

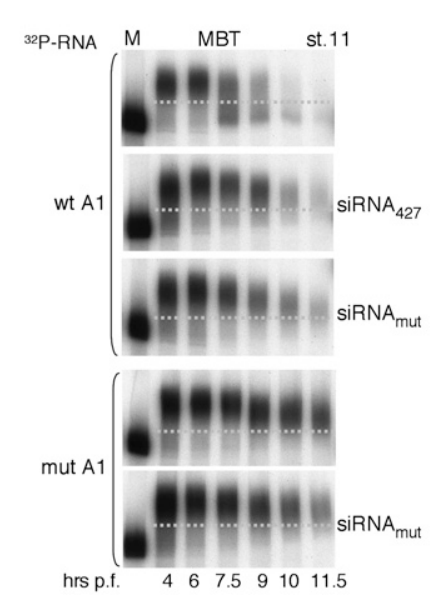

Figure 1. Inhibition of miR-427-dependent deadenylation by exogeneous siRNA. (A) Schematic representation of the chimeric $\beta$-globin'cyclin B2 3' UTR reporter mRNA (Gb・B2) indicating wild-type (wt) and inactivating mutant (mut) seed matches for miR-427 (MRE), cytoplasmic polyadenylation elements (CPE), and hexanucleotide polyadenylation signal (HEX). ${ }^{32}$ P-labeled $\mathrm{Gb} \bullet \mathrm{B} 2$ reporter RNAs with wild-type (top, middle) or mutant MREs were injected alone or together with siRNA $_{427}$ (200 fmol per embryo) into one- to two-cell embryos [1.5-2 h post-fertilization), and polyadenylation and deadenylation were monitored over time by denaturing PAGE of total RNAs (one embryo equivalent per lane). Marker lanes (M) show the nonpolyadenylated reporter RNAs prior to injection, and stippled lines demarcate polyadenylated from deadenylated reporter RNAs. For nucleotide sequences of $\operatorname{siRNA}_{427}$ (a miR427 mimic), siRNA mut (a variant designed to compensate for the seed match mutation in MREmut), and siRNA $_{N S}$ (a nonspecific commercial siRNA), see the Materials and Methods. (B) Impaired deadenylation of endogenous cyclin B2 mRNAs independent of siRNA sequence. Kinetics of deadenylation in untreated em-

bryos (Non-inj.) or embryos injected at the one-cell stage with siRNA 427 (left) or a non-specific siRNA $\mathrm{Ns}$ (right) (100 fmol per embryo) were monitored over time by Northern blot analyses of 3 '-terminal fragments of cyclin B2 mRNA generated by digestion with RNase H. Marker lanes (M) show 3'-terminal fragments lacking poly $(\mathrm{A})\left(\mathrm{A}_{0}\right) \cdot(C){ }^{32} \mathrm{P}$-labeled cyclin A1 3' UTR reporter RNAs (top diagram) with wild-type or mutant miR427 target sites (MRE) were injected alone or together with the indicated siRNAs (200 fmol per embryo), and polyadenylation and deadenylation were monitored over time as in $A$. 
by siRNA was due to blockage of miRNA production. Northern blot analysis revealed the absence of mature miR427 and the stabilization of pre-miR-427 in the presence of

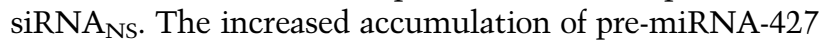
demonstrates that siRNA strongly inhibited Dicer processing, although miRNA destabilization might also have contributed to the absence of mature miR-427 (Fig. 2A,B). In contrast, accumulation of zygotic miR-19b and miR-16, which begins later, upon completion of gastrulation (stage 12), was only slightly affected (Fig. 2A, bottom panels), showing that siRNA-mediated inhibition of Dicer activity dissipates at later stages of embryogenesis.

The inhibition of Dicer activity was dose-dependent, as demonstrated by the extent of processing of injected ${ }^{32} \mathrm{P}$ labeled pre-miR-427 in early cleavage embryos (preMBT) containing varying amounts of siRNA (Fig. 2C). This dose response suggests that siRNAs titrate a factor that then becomes limiting for miRNA biogenesis. Inhibition of processing within 30 min of injection of siRNA ${ }_{N S}$ and premiR-427 into the cytoplasm indicates that the saturable factor is cytoplasmic, making it unlikely that the limiting factor is the pre-miRNA nuclear export factor Exportin 5 (Exp5) (Bohnsack et al. 2004; Lund et al. 2004; Ohrt et al. 2006).

Although siRNA-mediated inhibition of Dicer activity dissipated after gastrulation (which occurred normally), toxic effects of siRNA injection were evident at later stages of development. Tadpoles that developed from embryos injected with siRNA ${ }_{\mathrm{NS}}$ consistently had smaller eyes and heads, manifested fluid retention around the gut, were shorter overall, and were less pigmented than noninjected control tadpoles or tadpoles from $\mathrm{H}_{2} \mathrm{O}$-injected embryos (Fig. 2D; Supplemental Fig. S1). It is likely that these phenotypes result from disruption of the normal program of miR-427-mediated clearance of maternal mRNAs (like those of cyclins A1 and B2) during early stages of development (Giraldez 2010), although other consequences of the lack of Dicer activity or impairment of additional factors (see below) cannot be excluded.

\section{Dissipation of siRNA inhibition after $M B T$}

The recovery of pre-miRNA processing at later stages, after activation of zygotic transcription (Fig. 2A), indicated that embryos produced a factor that neutralized the inhibitory effects of siRNA. Western blot analyses showed that the levels of two key factors required for miRNA maturation (Exp5 and Dicer) did not change appreciably from the egg stage to well past MBT and gastrulation (Fig. 3A; data not shown). In contrast, the levels of Ago proteins began rising after MBT, showing that accumulation of Ago protein is developmentally controlled at this stage. The identity of the Ago proteins that increased could not be determined due to a lack of antibodies that can differentiate between various Xenopus Ago proteins (Supplemental Fig. S2A). The detected xlAgo proteins, as well as embryonic miR-427 (and maternal miRNAs), were efficiently coprecipitated by antiGW182 antibodies (Supplemental Fig. S2C), showing that they were incorporated into RISCs that could mediate deadenylation (CY Chen et al. 2009 ; Eulalio et al. 2009; Piao et al. 2010).

\section{Suppression of siRNA inhibition by exogenous Ago proteins}

In other organisms, expression of exogenous Ago proteins can increase the accumulation of endogenous miRNAs (Diederichs and Haber 2007), and Ago proteins complexed with Dicer and TRBP (HIV-1-transactivating response RNA-binding protein) are needed for efficient product release from Dicer of dsRNA cleavage products (Chendrimada et al. 2005; Gregory et al. 2005; Haase et al. 2005). Thus,

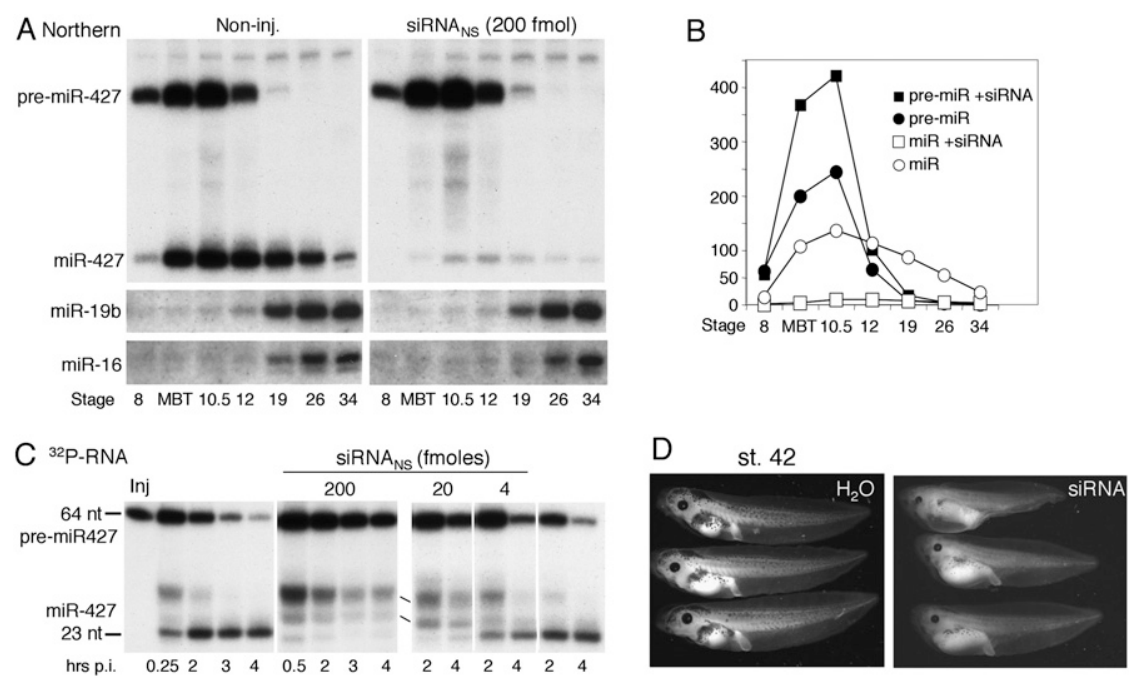

Figure 2. siRNA-mediated inhibition of miRNA biogenesis and disruption of tadpole development. (A) Impairment of miR427 biogenesis by siRNAs. Accumulation of endogenous $X$. laevis miRNAs in untreated embryos (Non-inj.) or embryos injected with siRNA $\mathrm{NS}_{\mathrm{N}}$ at the one-cell stage was monitored over time by Northern blot analyses of total RNAs (one embryo equivalent of total RNAs per lane). Individual blots were probed for miR-427, miRNA$19 \mathrm{~b}$, or miRNA-16, as indicated. $(B)$ PhosphorImager quantification of the miR-427 blots shown in $A$. $(C)$ Dosage-dependent inhibition of pre-miRNA processing. ${ }^{32} \mathrm{P}$ labeled pre-miR-427 RNAs were injected into one- to two-cell embryos alone lleft and right panels) or together with different amounts of siRNA $\mathrm{NS}_{\text {, }}$ and Dicer processing was monitored over time post-injection by denaturing PAGE of total RNAs (one embryo equivalent per lane). (D) Abnormal development of tadpoles derived from siRNA-injected embryos. One-cell embryos were injected with $100 \mathrm{fmol}$ of siRNA $\mathrm{NS}_{\mathrm{N}}$ or $\mathrm{H}_{2} \mathrm{O}$, and their development was monitored by visual inspection at stage 42 . Images of tadpoles developed from noninjected embryos are shown in Supplemental Fig. S1. 
Lund et al.

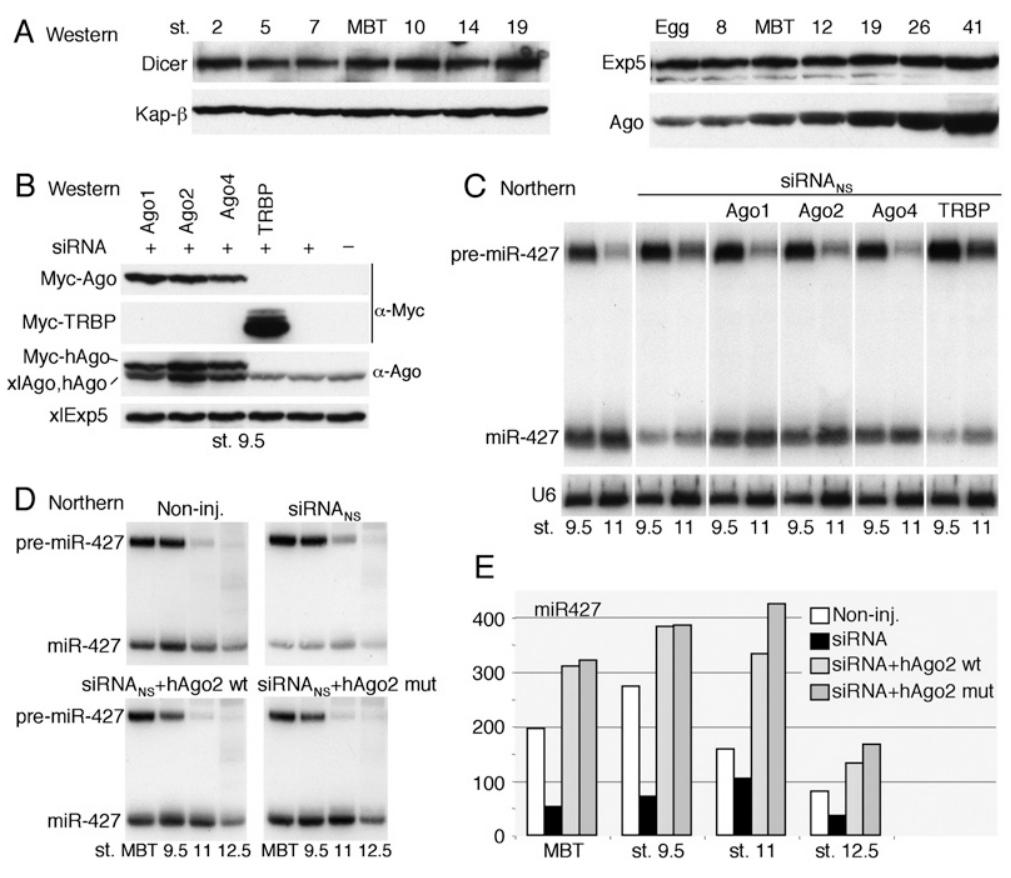

Figure 3. Titration of limiting Ago proteins by exogenous siRNA. (A) Developmental control of accumulation of xlAgo proteins in early embryos. Western blots of whole-cell extracts from eggs or embryos were probed with antibodies specific for the indicated proteins (cf. Supplemental Fig. S2); two (left panels) or one (right panels) embryo equivalents were loaded per lane. (B) Expression of exogenous Ago or TRBP proteins in early embryos. One-cell embryos were injected with siRNA $_{\mathrm{NS}}$ (30 fmol per embryo) alone or together with in vitro synthesized mRNAs encoding Myc-tagged human proteins, as indicated, and protein levels at stage 9.5 were monitored as in $A$. Note that the $\alpha$-Ago antibody (anti-EIF2C2, Abnova) detects all three hAgo proteins, albeit with different efficiencies (cf. $\alpha$-Ago and $\alpha-$ Myc signal). Kap- $\beta$ and xlExp5 served as loading controls in $A$ and $B$, respectively. $(C)$ Suppression of siRNA ${ }_{\mathrm{NS}}$-mediated inhibition of miR-427 processing by exogenous Ago proteins. Accumulation of miR-427 in embryos from the experiment shown in $B$ was monitored by Northern blot analyses as in Figure 2A. $(D)$ Limiting Ago proteins in early embryos. Embryos were programmed to express wild-type (wt) or catalytically inactive (mut) Myc-hAgo2 in the presence of siRNA $_{\mathrm{NS}}(20 \mathrm{fmol}$ per embryo), and miR-427 biogenesis was monitored as in $C$. $(E)$ Phosphorlmager quantification of mature miR-427 hybridization signals in $D$.

we reasoned that binding of siRNA to Ago proteins would reduce their availability and, hence, their ability to support Dicer activity.

To test whether inhibition of pre-miRNA processing by siRNA was due to depletion of available Ago proteins, we increased the quantity of these proteins in early embryos via injection of mRNAs encoding Myc-tagged human Ago-1, Ago-2, or Ago-4 (Fig. 3B). In the presence of coinjected siRNA $A_{\mathrm{NS}}$, each of these Ago proteins restored the accumulation of miR-427 to normal levels (Fig. 3C). In contrast, expression of high levels of exogenous TRBP, the dsRNA-binding cofactor of Dicer (Haase et al. 2005; Parker et al. 2008), was without effect, indicating that rescue of Dicer activity by exogenous Ago proteins was not merely a result of binding and sequestering dsRNA. Thus, we conclude that a limiting factor titrated by siRNA in early embryos is maternally derived Ago protein, which is needed at MBT for Dicer function, likely in product release. The zygotic xlAgo proteins that accumulate after MBT (Fig. 3A) are apparently sufficient to allow for Dicer activity at later times (cf. Fig. 2A).

To ask whether the endonuclease activity of Ago2 might play a role in suppression of siRNA inhibition, we monitored the processing of pre-miR-427 in embryos containing siRNA $\mathrm{NS}_{\mathrm{NS}}$ and either wild-type or a catalytically inactive mutant of hAgo2. The effects of the two forms were equivalent (Fig. 3D), showing that Ago2 catalytic activity is not essential for the rescue of Dicer activity, consistent with the fact that hAgol and hAgo4, which lack cleavage activity, can also function in this process (Fig. 3C). However, accumulation of miR-427 increased in embryos containing exogenous hAgo2 (Fig.
3E), indicating that Xenopus Ago proteins are limiting for miRNA biogenesis even in the absence of siRNA.

\section{Restoration of deadenylation by additional Ago proteins}

To determine whether the rescue of miRNA biogenesis by Ago proteins would also restore miR-427-mediated deadenylation in the presence of siRNA, we used a Gb•B2 reporter RNA with a sequence that was perfectly complementary to miR-427 (miR-427pm [perfect match]), in place of the wild-type $\mathrm{MRE}_{427}$ in the 3' UTR (Fig. 4). As expected (cf. Fig. 1), this reporter RNA remained polyadenylated and was stabilized through stage 9.5 in embryos containing siRNA $_{N S}$ (Fig. 4A, top panel). Expression of either form of hAgo2 resulted in deadenylation at MBT (Fig. 4A, middle and bottom panels), showing that the impairment of deadenylation by siRNA was likely due to a deficit of miR-427. The deadenylation that occurred by stage 11 in the absence of exogenous hAgo proteins (Fig. 4A, top panel) may be attributed to zygotic expression of xlAgo proteins (cf. Fig. $3 \mathrm{~A})$. These results also show that a miR- $427 \mathrm{pm}$ target site in the 3' UTR can function like the wild-type MRE.

\section{Lack of RNAi in embryos due to Ago2 deficiency}

Despite the equivalent activities of wild-type and mutant exogenous hAgo2 in restoring deadenylation, only the catalytically active hAgo 2 was able to promote endonucleolytic cleavage (RNAi) of the reporter RNA, producing discrete products (Fig. 4A, middle panel). Moreover, even in the absence of siRNA $\mathrm{N}_{\mathrm{NS}}$, embryos lacking exogenous Ago2 were unable to support RNAi, independent of whether 


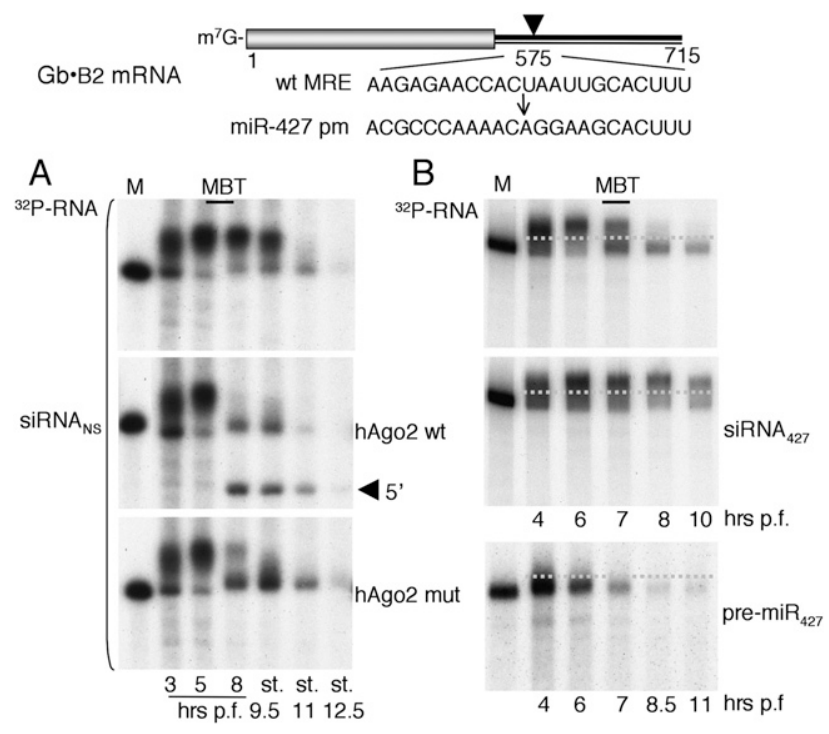

Figure 4. Rescue of deadenylation and RNAi deficiencies in

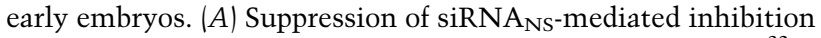
of deadenylation at MBT by exogenous Ago proteins. A ${ }^{32} \mathrm{P}-$ labeled $\mathrm{Gb} \bullet \mathrm{B} 2$ reporter RNA with a perfect match miR-427 target site in the $3^{\prime}$ UTR plus siRNA ${ }_{\text {NS }}(20$ fmol per embryo) was injected alone or together with synthetic mRNA encoding wild-type or mutant Myc-hAgo2, and reporter RNA stabilities were monitored over time as in Figure 1A. The arrowhead indicates the 5'-terminal RNAi cleavage product. Note that, in the absence of exogenous hAgo proteins, siRNA $\mathrm{Ns}_{\mathrm{N}}$-mediated inhibition of deadenylation was alleviated late in gastrulation (stages 11 and 12.5), coincident with increased accumulation of endogenous zygotic xlAgo proteins (cf. Fig. 3A and Supplemental Fig. S3B). (B) Lack of RNAi in the absence of exogenous Ago2. The ${ }^{32} \mathrm{P}$-labeled $\mathrm{Gb} \bullet \mathrm{B} 2$ reporter RNA was injected alone or together with siRNA 427 (100 fmol per embryo) or pre-miR-427 (Lund et al. 2009) into one- to two-cell embryos and analyzed as in $A$.

miR-427 (acting as the guide strand) was derived from endogenous or exogenous pre-miR-427 or from siRNA 427 (Fig. 4B); as expected (Lund et al. 2009), deadenylation was accelerated by exogenous pre-miR-427. These results indicate that early embryos (and oocytes) (see below) are deficient in Ago2 catalytic activity, in spite of the fact that they contain endogenous xlAgo2 mRNA (Supplemental Fig. S4).

Consistent with this conclusion, a Gb•B2 reporter RNA with a miR-427pm sequence within the coding region (Fig. 5A) was subject to siRNA 427 -mediated RNAi only in embryos that were supplemented with catalytically active hAgo2 (Figs. 5B,C; Supplemental Fig. S3). However, unlike reporters with miR-427 target sites in the 3' UTR, this reporter was not subject to deadenylation in either the absence (Fig. 5A) or presence (Fig. 5B) of siRNA 427 . Thus, the susceptibility of $\mathrm{Gb} \bullet \mathrm{B} 2$ reporter RNAs to deadenylation, but not to RNAi, is strongly affected by the location of the targeted $\mathrm{miR}-427 \mathrm{pm}$ sequence $(\mathrm{Wu}$ et al. 2008; Gu et al. 2009; Moretti et al. 2010). Importantly, exogenous hAgo2 also catalyzed RNAi of an endogenous mRNA, encoding cyclin B2, in the presence of a cyclin B2-specific siRNA (Fig. 5D). We conclude that the lack of xlAgo2 function explains why $X$. laevis embryos are unable to perform RNA-guided cleavage.

\section{Exogenous hAgo2 affects stability of siRNA 427}

The lack of endogenous xlAgo2 activity was also manifested in the stability of the injected siRNA ${ }_{427}$ (Fig. 5E). In the absence of exogenous Ago2 (data not shown) or the presence of hAgo2mut, both strands of siRNA remained stable for several hours, although the appearance of slower- or faster-migrating forms of siRNA 427 suggested that both strands were subject to turnover. However, in the presence of wild-type hAgo2, the passenger strand, but not the guide strand, was destabilized, consistent with the findings of others (Matranga et al. 2005; Rand et al. 2005).

Unexpectedly, we found that miR-427 generated from siRNA $_{427}$ in Ago2-expressing embryos (which support RNAi) (Fig. 4B; Supplemental Fig. S3A) was unable to promote efficient deadenylation of cyclin A1 3' UTR reporter RNA (Supplemental Fig. S5). This lack of activity contrasts with that of $\mathrm{miR}-427$ processed from pre-miR427, which readily promoted deadenylation prior to MBT, even in the absence of exogenous Ago proteins (Fig. 4B; Lund et al. 2009). The reason for this difference is unclear, but it suggests that formation of RISCs that function in deadenylation may depend on generation of miR-427 via Dicer processing (Gregory et al. 2005; Maniataki and Mourelatos 2005).

\section{Developmentally controlled Ago proteins do not support RNAi in oocytes}

The apparent deficiency of maternally derived Ago2 activity in early embryos led us to question whether Ago proteins were also subject to developmental control in oocytes. Western blot analyses revealed that immature (stage VI) oocytes contained low levels of Ago protein relative to eggs and early embryo, and that most of the oocyte-associated Ago protein was in follicle cells (Fig. 6A, lanes 1,2). However, the amount of Ago proteins was strongly up-regulated during progesterone-induced maturation, eventually matching but not exceeding that of early embryos (Fig. 6A, lanes 3-5), whereas the levels of Dicer and Exp5 remained essentially unchanged from immature oocytes through maturation and early embryogenesis (Fig. $6 \mathrm{~A}, \mathrm{C}$; data not shown).

To determine whether oocytes can support RNAi, we injected siRNA 427 plus the Gb•B2 reporter RNA containing a $427 \mathrm{pm}$ sequence in the $3^{\prime}$ UTR (cf. Fig. 4) into the cytoplasm (Fig. 6B) or nucleus (Supplemental Fig. S6) of stage VI oocytes. As expected (Fox et al. 1989; Sheets et al. 1994), the reporter RNA was polyadenylated in the nucleus (Supplemental Fig. S6) but not in the cytoplasm, unless the oocytes had undergone progesterone-induced maturation (Fig. 6B). Regardless of the site of injection or the state of polyadenylation, the reporter RNA was stable for at least $20 \mathrm{~h}$, and only in oocytes expressing exogenous hAgo 2 were 5 '-terminal and 3 '-terminal cleavage products detected. Moreover, the endogenous xlAgo proteins synthesized 
Lund et al.
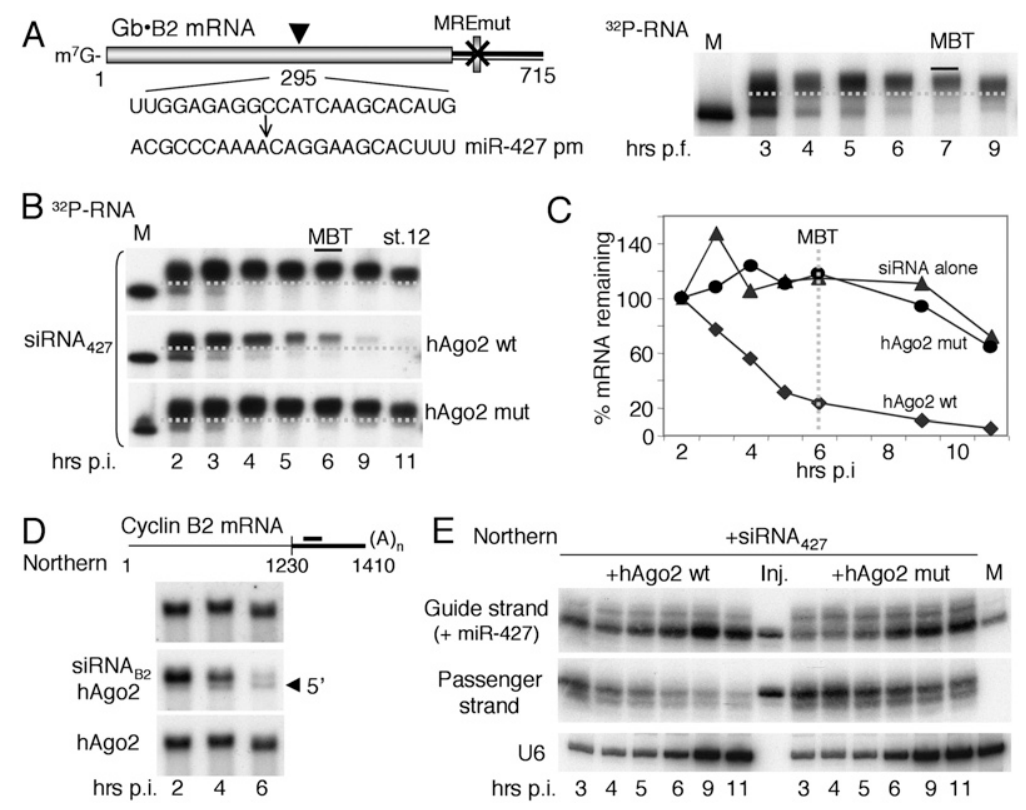

Figure 5. Lack of endogenous xlAgo2 catalytic activity in early embryos. (A) Inactivity of a coding region miR-427 target site. A ${ }^{32} \mathrm{P}$-labeled $\mathrm{Gb} \cdot \mathrm{B} 2$ reporter RNA with a perfect match miR-427 target sequence within the $\beta$-globin coding region and an inactive MREmut in the $3^{\prime}$ UTR was injected into one- to two-cell embryos and analyzed as in Figure 1A. Note that the miR-427pm target site in the coding region does not elicit deadenylation at MBT. (B) siRNA ${ }_{427}$-guided RNAi in preMBT embryos. The ${ }^{32}$ P-labeled reporter RNA plus $\operatorname{siRNA}_{427}(20 \mathrm{fmol}$ per embryo) was injected alone or together with synthetic mRNAs encoding wild-type or mutant Myc-tagged hAgo2 and analyzed as in $A$. $(C)$ Both 5 '-terminal and 3 '-terminal cleavage products were detected in the presence of hAgo2wt (Supplemental Fig. S3), and the extent of RNAi was quantified by PhosphorImager analyses. $(D)$ siRNA $_{\mathrm{B} 2}$-guided RNAi of endogenous cyclin B2 mRNA. Synthetic mRNA encoding wild-type myc-tagged hAgo2 was injected alone or together with siRNA $\mathrm{B} 2(30 \mathrm{fmol})$, and mRNA stability was monitored by Northern blot analysis of full-length cyclin B2 mRNA. The arrowhead indicates the $5^{\prime}-$ terminal RNAi cleavage product. siRNA $\mathrm{B}_{2}$ targets the 3' UTR of X. laevis cyclin B2 mRNA (black bar in top schematic). (E) Ago2-mediated destabilization of the passenger strand of siRNA ${ }_{427}$. Samples shown in $B$ were analyzed by Northern blot hybridization using probes specific for the guide or passenger strand of siRNA 427 . Marker lanes with one embryo equivalent of total RNA from noninjected stage 9.5 embryos (M) and siRNA ${ }_{427}$ prior to injection (Inj.) show that the amount of siRNA 427 injected was comparable with that of endogenous miR-m27. The increase in guide strand hybridization signals at 5-6 h post-injection reflects the onset of endogenous miR- 427 synthesis.

during maturation (Fig. 6A) provided no detectable Ago2 endonuclease activity. Similar results were obtained using the reporter RNA with the $427 \mathrm{pm}$ sequence in the coding region (data not shown). Thus, oocytes are also deficient in Ago2 catalytic activity, although they contain detectable amounts of xlAgo2 mRNA (Supplemental Fig. S4). We note that prior expression of hAgo2 in immature oocytes did not interfere with maturation or the accompanying up-regulation of xlAgo proteins (Fig. 6C).

\section{Absence of Ago2 cleavage activity in oocytes and embryos}

Finally, we used a separate assay to probe for endogenous Ago2 nuclease activity. The unusually short (42 nt) vertebrate pre-miR-451 (Fig. 7A) is not a substrate for processing by Dicer, but instead is processed directly by Ago 2 into a 30-nt intermediate, which undergoes subsequent 3 ' uridylation and trimming to the mature-sized, 23-nt-long miR-451 (Cheloufi et al. 2010; Cifuentes et al. 2010; Yang et al. 2010). Because the initial cleavage is strictly dependent on Ago 2 catalytic function, we tested whether in vitro synthesized pre-miR-451 could be processed in oocytes or embryos. In both cell types, pre-miR-451 was unstable and decayed over time, but produced no discrete cleavage products (Fig. 7B), confirming the absence of Ago2 activity. However, in cells expressing wild-type hAgo2, pre-miRNA451 gave rise to the expected 23-nt-long miR-451. The relative abundance of the 30 -nt intermediate in oocytes versus embryos suggested that trimming was more efficient in embryos. In cells expressing the catalytically inactive hAgo $2_{\text {mut }}$, pre-miR-451 was stabilized, indicat- ing that the RNA-binding activity of the mutant Ago2 protein was intact.

Other groups have generated novel miRNAs and siRNAs from synthetic precursors based on the scaffold structure of pre-miR-451 (Cheloufi et al. 2010; Cifuentes et al. 2010; Yang et al. 2010), leading us to test whether a similar precursor structure (Supplemental Fig. S7A) could provide a guide for cleavage of $\mathrm{Gb} \bullet \mathrm{B} 2$ reporter RNA in oocytes. A synthetic pre-miR-B2 RNA was processed in oocytes and embryos supplemented with active hAgo2, and the RNA product directed cleavage of the $\mathrm{Gb} \bullet \mathrm{B} 2$ reporter RNA (Supplemental Fig. S7B,C; data not shown). Thus, it should now be possible to perform RNAi on any endogenous mRNA in Xenopus oocytes or embryos by introduction of exogenous, catalytically active Ago2 and the appropriate pre-miR-451 scaffold RNA. In this regard, we note that expression of exogenous, catalytically active Ago2 did not perturb embryonic development (Supplemental Fig. S3; data not shown).

\section{Discussion}

We found that, during Xenopus oocyte maturation and early embryogenesis, expression of Ago proteins, unlike Exp5 and Dicer, is developmentally controlled, with the levels of Ago proteins being low in both immature oocytes and cleavage stage embryos, but rising after MBT. This dearth of Ago proteins during early development, including the surprising lack of Ago 2 catalytic activity, results in several unexpected phenotypes, such as inhibition by siRNAs of the production (and, hence, function) of miR-427 and the inability of oocytes and early embryos to support RNAi. 


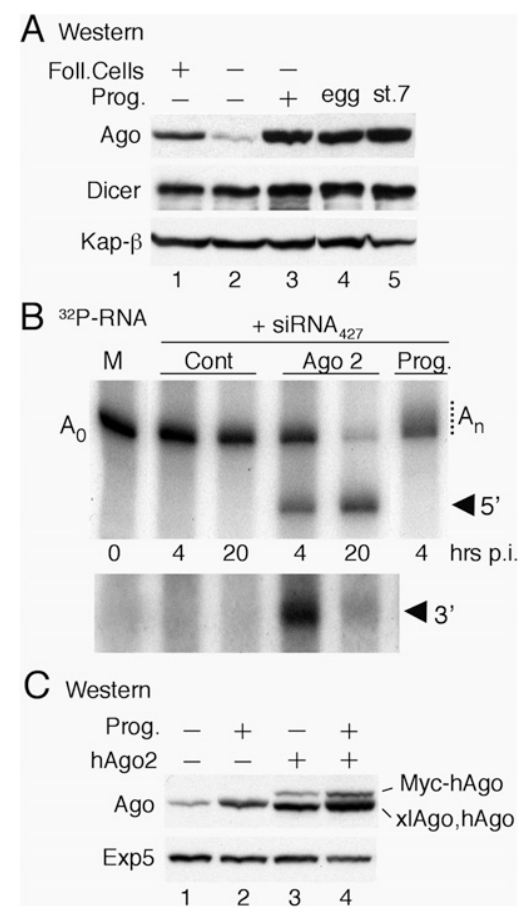

Figure 6. Absence of Ago2 catalytic activity from Xenopus oocytes. (A) Up-regulation of Ago protein levels during oocyte maturation. Whole-cell extracts from oocytes (lanes 1-3), eggs (lane 4), and stage 7 embryos (lane 5) were analyzed by Western blotting as in Figure 3. Immature (stage VI) oocytes were untreated (lane 1) or treated to remove follicle cells (lane 2) and matured by treatment with progesterone (lane 3). (B) Lack of RNAi in oocytes in the absence of exogenous Ago2. A ${ }^{32} \mathrm{P}$ labeled reporter RNA containing a perfect match miR-427 target site in the 3' UTR (cf. Fig. 4) was coinjected with siRNA ${ }_{427}(20$ fmol per embryo) into the cytoplasms of control oocytes (Cont), oocytes preinjected with synthetic mRNA encoding Myc-tagged hAgo2 (Ago2), or matured oocytes (Prog.), which supported polyadenylation $\left(\mathrm{A}_{\mathrm{n}}\right)$. The bottom panel shows a longer autoradiographic exposure for detection of the shorter $3^{\prime}$ cleavage product. $(C)$ Normal up-regulation of endogenous xlAgo proteins in the presence of exogenous hAgo2. Accumulation of Ago proteins in immature oocytes (lanes 1,3) or matured oocytes (lanes 2,4) in the absence (lanes 1,2) or presence of exogenous hAgo2 (lanes 3,4) was monitored as in $A$.

We propose that the low amount of maternal xlAgo proteins in early embryos (Fig. 3A) leads to easy saturation by exogenous siRNAs, and that the resulting siRNAoccupied Ago proteins are unable to bind additional RNAs. Thus, even modest amounts of siRNAs would deplete cells of Ago proteins needed for both release of cleavage products from Dicer during biogenesis of miRNAs and formation of new miR・RISCs. The consequent deficit of mature miR-427 (Fig. 2), as well as the reduction in Ago proteins available for RISC assembly, can account for our observation that siRNAs inhibit miR-427-mediated deadenylation of certain maternal mRNAs at MBT (Fig. 1).

Both the inhibitory effects of siRNA and the lack of RNAi likely result from limitations in the amounts and types of Xenopus Ago proteins in early embryos and oocytes (Figs. 3-5). For example, exogenous human Ago1, Ago4, or
Ago2 (including a variant of Ago2 that lacks endonuclease activity) restored Dicer processing in the presence of siRNA (Fig. 3), consistent with the overlap in functions of mammalian Ago proteins (Pillai et al. 2004; Su et al. 2009). However, only wild-type hAgo2 (but not a catalytically inactive mutant form of hAgo2) (Liu et al. 2004) enabled RNAi of both reporter and endogenous mRNAs, revealing the unexpected lack of Ago2 activity in early embryos and oocytes (Figs. 4-6).

Developmental control of xlAgo protein accumulation may contribute to the coordinated gene expression program through regulation of both the production and function of stage-specific miRNAs. Previously, we showed that the capacity for pre-miRNA processing by Dicer is greatly enhanced upon oocyte maturation (Lund and Dahlberg 2006) without a comparable increase in the level of Dicer protein, and we can now attribute that change in activity to the accumulation of Ago protein as oocytes mature (Fig. 6A; Diederichs and Haber 2007). It is likely that the severalfold increase in the level of Ago protein upon oocyte maturation results from activation of translation (rather than transcription) of xlAgo mRNAs, as transcription is not activated at this stage.

$X$. laevis Ago2 and Ago4 mRNAs are present in both oocytes and early embryos (Supplemental Fig. S4), in agreement with observations made in Xenopus tropicalis (Armisen et al. 2009), but only Ago2 mRNA increases in amounts upon activation of zygotic transcription after MBT. The accumulation of Ago proteins increases after MBT, but the identities of these Ago proteins are unknown. However, Ago2-associated cleavage activity is

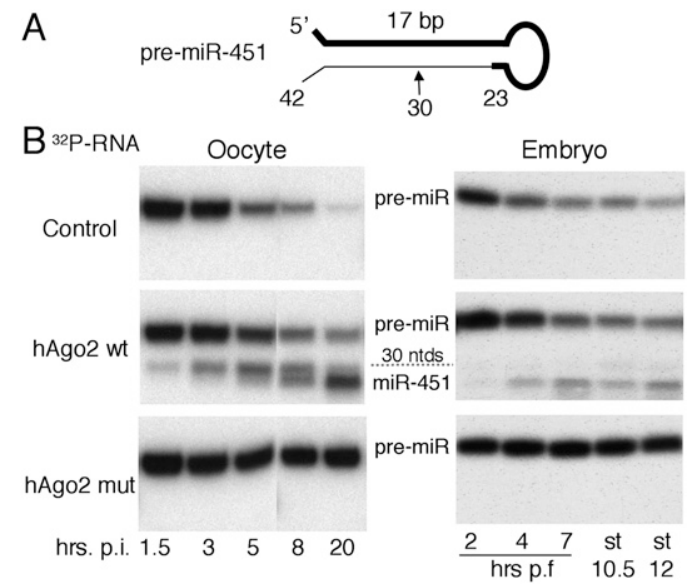

Figure 7. Requirement for exogenous Ago2 in pre-miR-451 processing. (A) Schematic representation of the evolutionarily conserved short hairpin structure of vertebrate pre-miR-451, indicating the mature miRNA (bold line) and the initial Ago2 cleavage site at nucleotide $30 .(B)^{32} \mathrm{P}$-labeled pre-miR-451 RNA was injected into oocytes (left) or one- to two-cell embryos (right) that were untreated (control) or programmed to express the indicated hAgo 2 proteins, and pre-miR-451 processing was monitored by denaturing PAGE. Embryo stages 10.5 and 12 correspond to $\sim 10$ and $\sim 12.5 \mathrm{~h}$ post-fertilization. The identity of the processing products was confirmed by RNase $\mathrm{T} 1$ fingerprinting (not shown). 
undetectable both before and shortly after MBT, during gastrulation (Fig. 4). It remains to be determined whether the absence of detectable Ago2 cleavage activity results from lack of xlAgo2 synthesis or from protein inactivation (Rudel et al. 2011). The ability of exogenous hAgo2 to function (Figs. 4-7) makes it unlikely that inhibition is involved.

Ago2 appears to be essential for development in most species, including mammals and zebrafish (Lykke-Andersen et al. 2008; Cheloufi et al. 2010; Cifuentes et al. 2010), and we are not aware of other systems in which detectable Ago2 activity is absent from normally growing vertebrate oocytes or early embryos. The advantages of regulating xlAgo2 activity during these stages of Xenopus development are unclear, as expression of exogenous hAgo 2 does not appear to have deleterious effects on either oocytes maturation (Fig. 6) or tadpole development (Supplemental Fig. S2). In contrast, the siRNA-induced depletion of available Ago proteins and the consequent deficit of zygotic miRNAs from early embryos lead to morphological defects at later stages of tadpole development (Fig. 2; Supplemental Fig. S1). It is likely that down-regulation of miR-427, which mediates clearance of maternal miRNAs (Lund et al. 2009; Giraldez 2010), contributes to this effect.

Double-stranded siRNAs have similar toxic effects in early zebrafish embryos, including sequence-independent blockage of miRNA-430 accumulation (the ortholog of miR-427) (Gruber et al. 2005; Zhao et al. 2008; Fjose and Zhao 2010; Wang et al. 2010). We suggest that, as in Xenopus, depletion of available zebrafish Ago proteins by saturation with siRNA provides a plausible explanation for this toxicity and inhibition.

Available Ago proteins (or other RISC components) are likely to be limiting in other systems (Koller et al. 2006; Castanotto et al. 2007). For example, elevated amounts of Ago proteins can suppress nonspecific toxicity of siRNAs in cultured cells or whole animals (Vickers et al. 2007; Grimm et al. 2010), increase levels of endogenous miRNAs (Diederichs and Haber 2007), and make RNAi more efficient (Diederichs et al. 2008; CM Chen et al. 2009). Moreover, competition for available Ago proteins likely accounts for the ability of exogenous siRNAs to increase expression of mRNAs that are controlled by unrelated cellular miRNAs (Persengiev et al. 2004; Khan et al. 2009).

We anticipate that our findings will facilitate analysis of gene expression and function during early development in Xenopus and zebrafish. Previous attempts to perform RNAi in these systems have been unsuccessful, but this may now be possible by use of exogenous Ago2 and appropriate guide RNAs.

\section{Materials and methods}

\section{DNA constructs}

The templates for synthesis of reporter RNAs pGb・B2 and pT7A1 and variants with mutations in the $\mathrm{MRE}_{427}$ have been described previously (Lund et al. 2009); pGb•B2 variants with perfect match miR-427 target sequences in the coding region (maintaining the reading frame) or 3' UTR were generated by
QuickChange Mutagenesis (Stratagene); mutagenic or synthetic oligonucleotides and primers are listed in Table 1. pcDNA3-based plasmids for expression of 3xMyc-tagged human Ago1, Ago2 (wild type and D669A mutant), or Ago4 proteins (gifts of G. Hannon; Liu et al. 2004) were modified by insertion of Xenopus cyclin B1 3' UTR sequences encoding CPE and HEX signals (Sheets et al. 1994) between the XbaI and ApaI sites immediately downstream from the hAgo coding regions. A similar plasmid expressing $3 x$ MychTRBP was made by substituting the human TRBP coding region (in the form of a BamHI-XbaI PCR product derived from pMALhTRBP (gift of B.L. Bass; Parker et al. 2008) for the hAgo2 coding region in pcDNA3-Ago2•B1 3' UTR. Templates for in vitro synthesis of pre-miR-451 and pre-miR-B2 RNAs were constructed by PCR from partially overlapping oligonucleotides (Table 1). Templates for synthesis of internally labeled RNA probes for miR16, miR-19b, and the passenger strand siRNA ${ }_{427}$ were generated according to the mirVana Probe construction protocol (Ambion).

\section{In vitro RNA synthesis}

Internally ${ }^{32} \mathrm{P}$-labeled reporter RNAs, pre-miR-427 RNA, and $\mathrm{U} 1_{\mathrm{Sm}}-$ and $\mathrm{U} 3 \mathrm{snRNAs}$ were synthesized by T7 RNA polymerase using $\alpha-\left[{ }^{32} \mathrm{P}\right]-\mathrm{UTP}$ as described previously (Pasquinelli et al. 1995; Lund et al. 2009). 5'-monophosphorylated, internally labeled premiR-451 and pre-miR-B2 RNAs were synthesized by SP6 polymerase using $\alpha-\left[{ }^{32} \mathrm{P}\right]-\mathrm{UTP}$ in the presence of $5^{\prime} \mathrm{GMP}[5 \mathrm{mM}]$ and low GTP $(0.1 \mathrm{mM})$ to promote transcription initiation with GMP. Unlabeled, $\mathrm{m}^{7} \mathrm{G}$-capped mRNAs encoding Myc-tagged hAgo and hTRBP proteins were synthesized by T7 polymerase using "MaxiTranscription" conditions (Promega)-including ARCA-CAP (5 $\mathrm{mM})$ (Epicentre Technologies); GTP (1 mM); ATP, UTP, and CTP (5 mM); and high $\mathrm{MgCl}_{2}(20 \mathrm{mM})$ - and production of full-length transcripts was verified by denaturing PAGE.

\section{Oocyte and embryo injection}

$X$. laevis oocytes and embryos were prepared using standard protocols (including manual dissection and defolliculization of oocytes) and were maintained at $18^{\circ} \mathrm{C}$ (oocytes) or $21^{\circ} \mathrm{C}-25^{\circ} \mathrm{C}$ (embryos) in requisite buffers, as detailed elsewhere (Sheets et al. 1995; Lund et al. 2009). ${ }^{32}$ P-labeled reporter RNAs ( 1-3 fmol) or pre-miRNAs ( 3-5 fmol) and unlabeled siRNAs ( 4-200 fmol) or mRNAs $(\sim 0.5 \mathrm{ng})$ were injected alone or together (as indicated in the figure legends) in a volume of $10-15 \mathrm{~nL}$ of $\mathrm{H}_{2} \mathrm{O}$ or 2 mM HEPES-KOH (pH 7). Unlabeled siRNA $_{427}$, siRNA mut $_{\text {, }}$ and siRNA $_{S T A B L E}$ (here called siRNA $A_{N S}$ ) (Table 1) were purchased from Dharmacon. For nuclear injection of oocytes, ${ }^{32} \mathrm{P}$-labeled reporter and $\mathrm{U} 3$ and $\mathrm{U} 1_{\mathrm{Sm}}-$ snRNAs (as controls for nuclear delivery and export) were mixed with blue dextran to verify the site of injection (Terns and Goldfarb 1998). For expression of exogenous hAgo or TRBP proteins, synthetic mRNAs (without a cyclin B1 3' UTR) were injected into oocyte cytoplasms $\sim 16-18 \mathrm{~h}$ prior to injection of reporter RNAs and siRNA 427 . Alternatively, synthetic mRNAs (with the cyclin B1 3' UTR that promotes cytoplasmic polyadenylation in embryos) were coinjected into embryos with reporter RNAs and siRNAs. For analyses of tadpole development, control and siRNA-treated or mock-treated embryos were incubated at room temperature $\left(21^{\circ} \mathrm{C}-23^{\circ} \mathrm{C}\right)$ in low-ionicstrength medium (MMR/4), staged according to Niewkoop and Faber (1967), and fixed in MEMFA for imaging (Mitchell et al. 2007).

\section{RNA analyses}

The isolation and analyses of injected reporter RNAs and siRNAs or endogenous cyclin B2 mRNA and miRNAs by denaturing 
Table 1. Oligonucleotides

\begin{tabular}{ccc}
\hline $\begin{array}{l}\text { Mutagenesis of pGB・B2 for generation of } 427 \text { perfect match }(\mathrm{pm}) \text { target sites } \\
\text { 427pm coding }\end{array}$ & fwd & GGTGGTGACATCTAACGCCCAAAACAGGAAGCACTTTGATG \\
& rev & CATCAAAGTGCTTCCTGTTTTGGGCGTTAGATGTCACCACC \\
$427 \mathrm{pm} \mathrm{3'}$ UTR & fwd & GTGACCCTTTCAACGCCCAAAACAGGAAGCACTTTTAACGTTGC \\
& rev & GCAACGTTAAAAGTGCTTCCTGTTTTGGGCGTTGAAAGGGTCAC
\end{tabular}

Synthesis of Cyclin B1 3' UTR for cloning into Myc-hAgo plasmids

B1 3' UTR 5' GGAATTCTAGAGTGTTTTTAATGTTTTACTGGTTTTAATAAAGCTC

B1 3' UTR 3' AACCCGGGCCCAGTACTGTTAAAATGAGCTTTATTAAAACCAG

Primers for PCR of hTRBP coding region

TRBP fwd CCAGGATCCTCATGAGTGAAGAGGAGCAAGGCTCC

rev GCCTCTTAGAAGCTTTCACTTGCTGCCTGCCATGATCTT

Templates for in vitro synthesis of pre-miR-451 and pre-miR-B2

miR-451 fwd GGGATTTAGGTGACACTATAGAATACTTACCATTACTGAGTTT

rev GATAATACTTACCATTACTAAACTCAGTAATGGTAAGTATTCT

miR-B2 fwd GGGATTTAGGTGACACTATAGAATAGCAGCATTTGCCAGCAG

rev GATAATAGCAGCATTTGCCACTGCTGGCAAATGCTGCTATTC

mirVana templates for in vitro synthesis of Northern blots probes

siRNA $_{427}$ guide TAAGAAAGTGCTTCCTGTTTTGGGCGTTCCTGTCTC

siRNA $_{427}$ passenger GCCCAAAACAGGAAGCACTTTTTCCTGTCTC

miR-19b TGTGCAAATCCATGCAAAACTGACCTGTCTC

miR-16 TAGCAGCACGTAAATATTGGCCCCTGTCTC

siRNAs (guide strand in bold)

siRNA-427 5'-AAAGUGCUUCCUGUUUUGGGCGU-3';

siRNA-mut 5'-AAACACCUUCCUGUUUUGGGCGU-3';

siRNA-B2 5'-UUAAAAGUGCAAUUAGUGGUU-3';

siRNA-NS 5'-UAGCGACUAAACACAUCAUdTdT-3';

5'-GCCCAAAACAGGAAGCACUUUUU-3'

5'-GCCCAAAACAGGAAGGUGUUUUU-3'

5'-CCACUAAUUGCACUUUUAAUU-3'

5'-AUGAUGUGUUUAGUCGCUAdTdT-3'

Primers for semiquantitative PCR of $X$. laevis mRNAs Ago2 (287 bp)

fwd AGCATGACAGCGCTGAAGGTAGCCA

Ago2 (214 bp)

rev GCGGTTGGGACGGAAGGCTGGT

Ago4 (203 bp)

fwd TGCCCCAGGGCAGACCTCCTGT

rev AGCAGCTCCCGAACCATGGCA

Xbra

fwd GCCAGCAGGAACTACAGTGGACAGC

ODC

rev AAACAGACCGCGTGCACCGCACA

fwd TGGACACCCGTTGCGCCACCATC

rev AGGGACCCCCAGCAATTCAGGCCCA

fwd GGGGACCAACGTGTGATGGGCTGG

rev TCTCCAACTTGCAGCTCCGGCAGC

All are deoxynucleotides, except for the siRNAs, and are shown $5^{\prime}$ to $3^{\prime}$.

PAGE and Northern blotting were done as described previously (Lund et al. 2009). U6 RNA was included as a loading control. In Figure 2 and Supplemental Figure S2, the hybridization signals for the low-abundance miR-19b and miR-16 were $\sim 100$-fold weaker than for miR-427 using internally ${ }^{32} \mathrm{P}$-labeled probes of similar specific activities, due to large differences in expression levels (Watanabe et al. 2005; Lund et al. 2009).

For analyses of endogenous mRNAs by RT-PCR, total RNAs were isolated by extraction with Tri-Reagent (Ambion), and equivalent amounts of RNA $(2 \mu \mathrm{g})$ were reverse-transcribed using the "RNA to cDNA EcoDry" (Clontech) cDNA kit according to the manufacturers' instructions. Standard PCR was carried out with MasterAmp Tth DNA polymerase (Epicentre) and genespecific primers (listed in Table 1) for 32 or 35 cycles, as indicated in Supplemental Figure S4. The DNA sequences of X. laevis genes used for PCR primer design were obtained from GenBank (accession numbers BC077863 for Ago2 [eif2c2], NM_001096105 for Ago4 [eif2c4], M77243 for Xbra, and X56316 for ODC. Xbra (Smith et al. 1991) and ODC (Kofron et al. 2004) serve as internal controls for stage-specific and housekeeping gene expression, respectively.

\section{Antibodies}

The specificities of several antibodies-including anti-Ago $2 \mathrm{~A} 8$ $\mathrm{mAb}$ (gift of Z. Mourelatos; Nelson et al. 2007), anti-EIF2C2 mAb (Abnova \#H00027161-M01), anti-Ago2 rabbit polyclonal (Millipore/ Upstate Biotechnologies \#07-590), human antiserum \#18033 against hGW182 (gift of M. Fritzler; Eystathioy et al. 2002), and rabbit polyclonal anti-Dicer \#349 (gift of W. Filipowicz; Kotaja et al. 2006) - were tested by Western blotting and immunoprecipitation (Fig. 3; Supplemental Fig. S3; data not shown). Myctagged proteins were detected with anti-Myc mAb 9E10 (Santa Cruz Biotechnology). Rabbit polyclonal antibodies against Xenopus Exp5 (Bohnsack et al. 2004) and Karyopherin- $\beta$ were gifts of D. Görlich and M.S. Moore, respectively.

\section{Western blots and immunoprecipitation}

For Western blots, whole-cell extracts of pools of three to 10 oocytes or embryos were prepared by manual homogenization in 10-20 $\mu \mathrm{L}$ per embryo of $20 \mathrm{mM}$ Tris- $\mathrm{Hcl}(\mathrm{pH} 7.5), 50 \mathrm{mM} \mathrm{NaCl}$, and $1 \mathrm{mM}$ EDTA with protease inhibitor (Roche), followed by centrifugation at $5000 \mathrm{rpm}(2000 \mathrm{~g})$ for $10 \mathrm{~min}$ at $4{ }^{\circ} \mathrm{C}$ to remove 
insoluble material. From 0.5 to two oocyte or embryo equivalents of clarified extracts were separated in 7\% (30:0.8) SDSPAGE and then transferred electrophoretically to Immobilon-P polyvinylidene difluoride membranes (Millipore). Membranes were probed with primary antibodies in TBS-T $(10 \mathrm{mM}$ Tris- $\mathrm{HCl}$ at $\mathrm{pH} 8.0,150 \mathrm{mM} \mathrm{NaCl}, 1 \mathrm{mM}$ EDTA, $0.25 \%$ Tween 20 ) containing $5 \%$ powdered milk (Carnation) followed by secondary antibodies (conjugated to horseradish peroxidase) and ECL, using Super signal (Thermo Scientific Pierce) detected by exposure to BioMax XAR film (Kodak). Karyopherin $\beta$ and Exp5 were included as loading controls. For coimmunoprecipitation assays (Supplemental Fig. S2C), antibodies were bound to Protein A/GPLUS-Agarose (Santa Cruz Biotechnology) in immunoprecipitation buffer $(20 \mathrm{mM}$ Tris- $\mathrm{Hcl}$ at $\mathrm{pH} 7.5,200 \mathrm{mM} \mathrm{NaCl}, 2 \mathrm{mM}$ DTT) and incubated overnight at $4^{\circ} \mathrm{C}$ with three to nine embryo equivalents of clarified extracts prepared with immunoprecipitation buffer containing $0.1 \mathrm{U} / \mu \mathrm{L}$ RNasin Plus (Promega) and EDTA-free protease inhibitors (Roche). After removal of unbound material (supernatant) and washing four times with immunoprecipitation buffer, the agarose beads were split evenly to allow for both protein and RNA analyses by Western and Northern blots, respectively.

\section{Acknowledgments}

We thank B.L. Bass, W. Filipowicz, M.J. Fritzler, D. Görlich, G. Hannon, M.S. Moore and Z. Mourelatos for reagents. This work was supported by a University of Wisconsin Hilldale Professorship to J.E.D. and royalties from the Wisconsin Alumni Research Foundation.

\section{References}

Amaya E, Musci TJ, Kirschner MW. 1991. Expression of a dominant negative mutant of the FGF receptor disrupts mesoderm formation in Xenopus embryos. Cell 66: 257-270.

Armisen J, Gilchrist MJ, Wilczynska A, Standart N, Miska EA. 2009. Abundant and dynamically expressed miRNAs, piRNAs, and other small RNAs in the vertebrate Xenopus tropicalis. Genome Res 19: 1766-1775.

Audic Y, Anderson C, Bhatty R, Hartley RS. 2001. Zygotic regulation of maternal cyclin A1 and B2 mRNAs. Mol Cell Biol 21: 1662-1671.

Bartel DP. 2004. MicroRNAs: genomics, biogenesis, mechanism, and function. Cell 116: 281-297.

Bohnsack MT, Czaplinski K, Gorlich D. 2004. Exportin 5 is a RanGTP-dependent dsRNA-binding protein that mediates nuclear export of pre-miRNAs. RNA 10: 185-191.

Castanotto D, Sakurai K, Lingeman R, Li H, Shively L, Aagaard L, Soifer H, Gatignol A, Riggs A, Rossi JJ. 2007. Combinatorial delivery of small interfering RNAs reduces RNAi efficacy by selective incorporation into RISC. Nucleic Acids Res 35: 5154-5164.

Cheloufi S, Dos Santos CO, Chong MM, Hannon GJ. 2010. A dicer-independent miRNA biogenesis pathway that requires Ago catalysis. Nature 465: 584-589.

Chen CM, Chiu SL, Shen W, Cline HT. 2009. Co-expression of Argonaute2 enhances short hairpin RNA-induced RNA interference in Xenopus CNS neurons in vivo. Front Neuro Circuits 3: 25. doi: 10.3389/neuro.04.025.2009.

Chen CY, Zheng D, Xia Z, Shyu AB. 2009. Ago-TNRC6 triggers microRNA-mediated decay by promoting two deadenylation steps. Nat Struct Mol Biol 16: 1160-1166.

Chendrimada TP, Gregory RI, Kumaraswamy E, Norman J, Cooch N, Nishikura K, Shiekhattar R. 2005. TRBP recruits the Dicer complex to Ago2 for microRNA processing and gene silencing. Nature 436: 740-744.

Cifuentes D, Xue H, Taylor DW, Patnode H, Mishima Y, Cheloufi S, Ma E, Mane S, Hannon GJ, Lawson ND, et al. 2010. A novel miRNA processing pathway independent of Dicer requires Argonaute2 catalytic activity. Science 328: 1694-1698.

Czech B, Hannon GJ. 2011. Small RNA sorting: matchmaking for Argonautes. Nat Rev Genet 12: 19-31.

Diederichs S, Haber DA. 2007. Dual role for argonautes in microRNA processing and posttranscriptional regulation of microRNA expression. Cell 131: 1097-1108.

Diederichs S, Jung S, Rothenberg SM, Smolen GA, Mlody BG, Haber DA. 2008. Coexpression of Argonaute-2 enhances RNA interference toward perfect match binding sites. Proc Natl Acad Sci 105: 9284-9289.

Ekker SC. 2000. Morphants: a new systematic vertebrate functional genomics approach. Yeast 17: 302-306.

Eulalio A, Huntzinger E, Izaurralde E. 2008. Getting to the root of miRNA-mediated gene silencing. Cell 132: 9-14.

Eulalio A, Tritschler F, Izaurralde E. 2009. The GW182 protein family in animal cells: new insights into domains required for miRNA-mediated gene silencing. RNA 15: 1433-1442.

Eystathioy T, Chan EK, Tenenbaum SA, Keene JD, Griffith K, Fritzler MJ. 2002. A phosphorylated cytoplasmic autoantigen, GW182, associates with a unique population of human mRNAs within novel cytoplasmic speckles. Mol Biol Cell 13: $1338-1351$.

Fabian MR, Sonenberg N, Filipowicz W. 2010. Regulation of mRNA translation and stability by microRNAs. Annu Rev Biochem 79: 351-379.

Fiose A, Zhao XF. 2010. Inhibition of the microRNA pathway in zebrafish by siRNA. Methods Mol Biol 629: 239-255.

Fox CA, Sheets MD, Wickens MP. 1989. Poly(A) addition during maturation of frog oocytes: distinct nuclear and cytoplasmic activities and regulation by the sequence UUUUUAU. Genes Dev 3: 2151-2162.

Giraldez AJ. 2010. MicroRNAs, the cell's Nepenthe: clearing the past during the maternal-to-zygotic transition and cellular reprogramming. Curr Opin Genet Dev 20: 369375.

Giraldez AJ, Mishima Y, Rihel J, Grocock RJ, Van Dongen S, Inoue K, Enright AJ, Schier AF. 2006. Zebrafish miR-430 promotes deadenylation and clearance of maternal mRNAs. Science 312: 75-79.

Gregory RI, Chendrimada TP, Cooch N, Shiekhattar R. 2005. Human RISC couples microRNA biogenesis and posttranscriptional gene silencing. Cell 123: 631-640.

Grimm D, Wang L, Lee JS, Schurmann N, Gu S, Borner K, Storm TA, Kay MA. 2010. Argonaute proteins are key determinants of RNAi efficacy, toxicity, and persistence in the adult mouse liver. J Clin Invest 120: 3106-3119.

Gruber J, Manninga H, Tuschl T, Osborn M, Weber K. 2005. Specific RNAi mediated gene knockdown in zebrafish cell lines. RNA Biol 2: 101-105.

Gu S, Jin L, Zhang F, Sarnow P, Kay MA. 2009. Biological basis for restriction of microRNA targets to the $3^{\prime}$ untranslated region in mammalian mRNAs. Nat Struct Mol Biol 16: 144-150.

Haase AD, Jaskiewicz L, Zhang H, Laine S, Sack R, Gatignol A, Filipowicz W. 2005. TRBP, a regulator of cellular PKR and HIV-1 virus expression, interacts with Dicer and functions in RNA silencing. EMBO Rep 6: 961-967.

Heasman J, Kofron M, Wylie C. 2000. $\beta$-Catenin signaling activity dissected in the early Xenopus embryo: a novel antisense approach. Dev Biol 222: 124-134. 
Hulstrand AM, Schneider PN, Houston DW. 2010. The use of antisense oligonucleotides in Xenopus oocytes. Methods 51: 75-81.

Khan AA, Betel D, Miller ML, Sander C, Leslie CS, Marks DS. 2009. Transfection of small RNAs globally perturbs gene regulation by endogenous microRNAs. Nat Biotechnol 27: 549-555.

Kim VN, Han J, Siomi MC. 2009. Biogenesis of small RNAs in animals. Nature reviews 10: 126-139.

Kofron M, Wylie C, Heasman J. 2004. The role of Mixer in patterning the early Xenopus embryo. Development 131: 2431-2441.

Koller E, Propp S, Murray H, Lima W, Bhat B, Prakash TP, Allerson CR, Swayze EE, Marcusson EG, Dean NM. 2006. Competition for RISC binding predicts in vitro potency of siRNA. Nucleic Acids Res 34: 4467-4476.

Kotaja N, Bhattacharyya SN, Jaskiewicz L, Kimmins S, Parvinen M, Filipowicz W, Sassone-Corsi P. 2006. The chromatoid body of male germ cells: similarity with processing bodies and presence of Dicer and microRNA pathway components. Proc Natl Acad Sci 103: 2647-2652.

Liu J, Carmell MA, Rivas FV, Marsden CG, Thomson JM, Song JJ, Hammond SM, Joshua-Tor L, Hannon GJ. 2004. Argonaute2 is the catalytic engine of mammalian RNAi. Science 305: $1437-1441$.

Lund E, Dahlberg JE. 2006. Substrate selectivity of Exportin 5 and Dicer in the biogenesis of microRNAs. Cold Spring Harb Symp Quant Biol 71: 59-66.

Lund E, Guttinger S, Calado A, Dahlberg JE, Kutay U. 2004. Nuclear export of microRNA precursors. Science 303: 95-98.

Lund E, Liu M, Hartley RS, Sheets MD, Dahlberg JE. 2009. Deadenylation of maternal mRNAs mediated by miR-427 in Xenopus laevis embryos. RNA 15: 2351-2363.

Lykke-Andersen K, Gilchrist MJ, Grabarek JB, Das P, Miska E, Zernicka-Goetz M. 2008. Maternal Argonaute 2 is essential for early mouse development at the maternal-zygotic transition. Mol Biol Cell 19: 4383-4392.

Maniataki E, Mourelatos Z. 2005. A human, ATP-independent, RISC assembly machine fueled by pre-miRNA. Genes Dev 19: $2979-2990$

Matranga C, Tomari Y, Shin C, Bartel DP, Zamore PD. 2005. Passenger-strand cleavage facilitates assembly of siRNA into Ago2-containing RNAi enzyme complexes. Cell 123: 607-620.

Mitchell T, Jones EA, Weeks DL, Sheets MD. 2007. Chordin affects pronephros development in Xenopus embryos by anteriorizing presomitic mesoderm. Dev Dyn 236: 251-261.

Moretti F, Thermann R, Hentze MW. 2010. Mechanism of translational regulation by miR-2 from sites in the $5^{\prime}$ untranslated region or the open reading frame. RNA 16: 2493-2502.

Nelson PT, De Planell-Saguer M, Lamprinaki S, Kiriakidou M, Zhang P, O'Doherty U, Mourelatos Z. 2007. A novel monoclonal antibody against human Argonaute proteins reveals unexpected characteristics of miRNAs in human blood cells. RNA 13: 1787-1792.

Newport J, Kirschner M. 1982a. A major developmental transition in early Xenopus embryos: I. Characterization and timing of cellular changes at the midblastula stage. Cell 30: 675-686.

Newport J, Kirschner M. 1982b. A major developmental transition in early Xenopus embryos: II. Control of the onset of transcription. Cell 30: 687-696.

Niewkoop PD, Faber J. 1967. Normal table of Xenopus laevis (Daudin). North Holland, Amsterdam.

Ohrt T, Merkle D, Birkenfeld K, Echeverri CJ, Schwille P. 2006. In situ fluorescence analysis demonstrates active siRNA exclusion from the nucleus by Exportin 5. Nucleic Acids Res 34: 1369-1380.
Parker GS, Maity TS, Bass BL. 2008. dsRNA binding properties of RDE-4 and TRBP reflect their distinct roles in RNAi. J Mol Biol 384: 967-979.

Pasquinelli AE, Dahlberg JE, Lund E. 1995. Reverse 5' caps in RNAs made in vitro by phage RNA polymerases. RNA 1: 957-967.

Perrimon N, Ni JQ, Perkins L. 2010. In vivo RNAi: today and tomorrow. Cold Spring Harb Perspect Biol 2: a003640. doi: 10.1101/cshperspect.a003640.

Persengiev SP, Zhu X, Green MR. 2004. Nonspecific, concentration-dependent stimulation and repression of mammalian gene expression by small interfering RNAs (siRNAs). RNA 10: $12-18$.

Piao X, Zhang X, Wu L, Belasco JG. 2010. CCR4-NOT deadenylates mRNA associated with RNA-induced silencing complexes in human cells. Mol Cell Biol 30: 1486-1494.

Pillai RS, Artus CG, Filipowicz W. 2004. Tethering of human Ago proteins to mRNA mimics the miRNA-mediated repression of protein synthesis. RNA 10: 1518-1525.

Rand TA, Petersen S, Du F, Wang X. 2005. Argonaute2 cleaves the anti-guide strand of siRNA during RISC activation. Cell 123: 621-629.

Rudel S, Wang Y, Lenobel R, Korner R, Hsiao HH, Urlaub H, Patel D, Meister G. 2011. Phosphorylation of human Argonaute proteins affects small RNA binding. Nucleic Acids Res 39: 2330-2343.

Sheets MD, Fox CA, Hunt T, Vande Woude G, Wickens M. 1994. The 3'-untranslated regions of c-mos and cyclin mRNAs stimulate translation by regulating cytoplasmic polyadenylation. Genes Dev 8: 926-938.

Sheets MD, Wu M, Wickens M. 1995. Polyadenylation of c-mos mRNA as a control point in Xenopus meiotic maturation. Nature 374: 511-516.

Smith JC, Price BM, Green JB, Weigel D, Herrmann BG. 1991. Expression of a Xenopus homolog of Brachyury $(\mathrm{T})$ is an immediate-early response to mesoderm induction. Cell 67: 79-87.

Su H, Trombly MI, Chen J, Wang X. 2009. Essential and overlapping functions for mammalian Argonautes in microRNA silencing. Genes Dev 23: 304-317.

Terns MP, Goldfarb DS. 1998. Nuclear transport of RNAs in microinjected Xenopus oocytes. Methods Cell Biol 53: 559589.

Valencia-Sanchez MA, Liu J, Hannon GJ, Parker R. 2006. Control of translation and mRNA degradation by miRNAs and siRNAs. Genes Dev 20: 515-524.

Vickers TA, Lima WF, Nichols JG, Crooke ST. 2007. Reduced levels of Ago2 expression result in increased siRNA competition in mammalian cells. Nucleic Acids Res 35: 6598-6610.

Wang L, Zhou JY, Yao JH, Lu DR, Qiao XJ, Jia W. 2010. U6 promoter-driven siRNA injection has nonspecific effects in zebrafish. Biochem Biophys Res Commun 391: 1363-1368.

Watanabe T, Takeda A, Mise K, Okuno T, Suzuki T, Minami N, Imai H. 2005. Stage-specific expression of microRNAs during Xenopus development. FEBS Lett 579: 318-324.

Wu L, Fan J, Belasco JG. 2008. Importance of translation and nonnucleolytic ago proteins for on-target RNA interference. Curr Biol 18: 1327-1332.

Yang JS, Maurin T, Robine N, Rasmussen KD, Jeffrey KL, Chandwani R, Papapetrou EP, Sadelain M, O'Carroll D, Lai EC. 2010. Conserved vertebrate mir-451 provides a platform for Dicer-independent, Ago2-mediated microRNA biogenesis. Proc Natl Acad Sci 107: 15163-15168.

Zhao XF, Fjose A, Larsen N, Helvik JV, Drivenes O. 2008. Treatment with small interfering RNA affects the microRNA pathway and causes unspecific defects in zebrafish embryos. FEBS J 275: 2177-2184. 


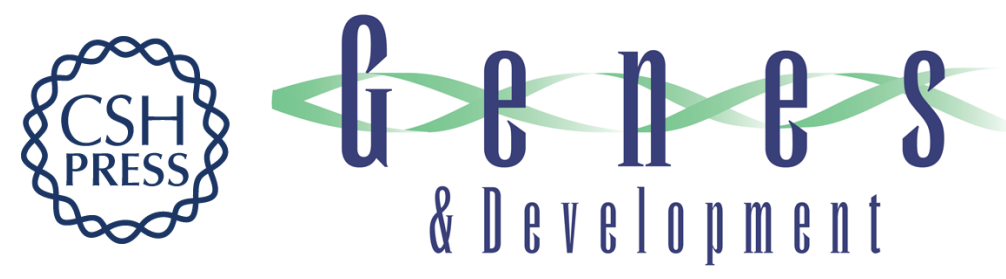

\section{Limiting Ago protein restricts RNAi and microRNA biogenesis during early development in Xenopus laevis}

Elsebet Lund, Michael D. Sheets, Susanne Blaser Imboden, et al.

Genes Dev. 2011, 25: originally published online May 16, 2011

Access the most recent version at doi:10.1101/gad.2038811

\section{Supplemental http://genesdev.cshlp.org/content/suppl/2011/05/06/gad.2038811.DC1 \\ Material}

Related Content RNAi in Xenopus: look before you leap

Alex S. Flynt and Eric C. Lai

Genes Dev. June , 2011 25: 1105-1108

References This article cites 68 articles, 29 of which can be accessed free at:

http://genesdev.cshlp.org/content/25/11/1121.full.html\#ref-list-1

Articles cited in:

http://genesdev.cshlp.org/content/25/11/1121.full.html\#related-urls

\section{License}

Email Alerting

Service

Receive free email alerts when new articles cite this article - sign up in the box at the top right corner of the article or click here.

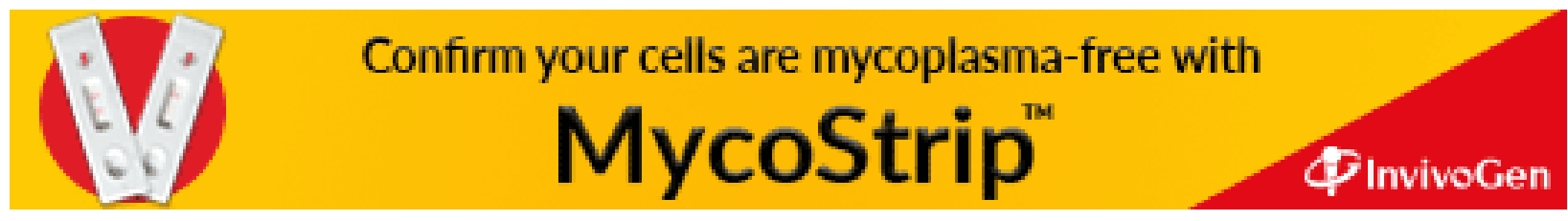

